\title{
A TOOL TO MEASURE MATURITY OF AN EMPLOYEE SUGGESTION SCHEME
}

\author{
Flevy Lasrado, Boštjan Gomišček \\ University of Wollongong in Dubai, Faculty of Business \\ Corresponding author: \\ Flevy Lasrado \\ University of Wollongong in Dubai \\ Faculty of Business \\ Block 15, Knowledge Village \\ P. O. Box 20183, Dubai, UAE \\ phone: 00971504582851 \\ e-mail: FlevyLasrado@uowdubai.ac.ae
}

Received: 13 April 2015

Accepted: 13 May 2015

\begin{abstract}
Employee Suggestion Schemes have been used in organizations for a long time due to the fact that they enable fostering of creative ability of employees. However, they must be used effectively and in a sustainable manner to better the creativity and innovation capacity of organizations in order to improve competitive advantage. Therefore there is a need to understand the maturity of Employee Suggestion Schemes. This paper proposes a new, structured evaluation tool for assessing an organizational Employee Suggestion Scheme maturity. It suggests five building blocks: Leadership and Work Environment, System Capability, System Effectiveness, Organizational Encouragement and System Barriers, each of them characterized by several relevant indicators and an assessment/grading scale in order for an organization to be able to determine the maturity level of their Employee Suggestion Scheme as: Initial stage, Development stage or Advanced stage. Organizations should apply this tool to assess the maturity level of their Employee Suggestion Scheme and draw a roadmap for its improvements.
\end{abstract}

KEYWORDS

quality management, measurement, model, system, Employee Suggestion Scheme, innovation.

\section{Introduction}

An Employee Suggestion Scheme (ESS) is described as a formalized mechanism that encourages employees to contribute constructive ideas for improving the organization in which they work [1] or an ESS elicits suggestions from employees, classifies them, and dispatches them to experts for evaluation [2]. ESS can be seen as an un-untapped reservoir of effort and knowledge that could improve organizational processes and effectiveness [3]. Suggestion schemes are also sources of innovation as they promote the implementation of new routines and facilitate the improvement and refinement of existing routines $[3,4]$. Employee suggestion schemes therefore play a pivotal role for organizations wishing to become more innovative [5]. New and creative ideas are essential to solve problems, economize work hours, spare the efforts of many people, and meet their social and cultural needs [6]. After all, untapped employee creativity is a wasted organizational resource - effective employee suggestions schemes help convert that waste into wealth [7].

Employee suggestion schemes create a win-win situation for employers and employees alike. However, despite many benefits of the employee suggestion schemes, sustaining them is still a challenge for organizations [8].

Although the interest and practice in using the ESS is widespread and it is recognized that innovation is an important source of growth for many organizations, sustaining innovation is not easy. The assessments of maturity in suggestion schemes are less common, though there is some evidence of the 
research in this filed [8]. The lists of critical success factors and barriers to suggestion schemes are robust; however, a gap exists in the literature due to absence of a formal mechanism to assess the maturity of the ESS. Organizations need to assess their schemes for its sustainable growth and in order to recognize if proper, supporting conditions exist for their ESS to flourish [9].

This paper is an attempt to introduce a structured tool to assess the maturity of an ESS. The purpose of this paper is to introduce a novel, structured tool that can be applied to measure and assess the maturity of an ESS. This tool is based on a framework published by [9]. It suggests five factors for assessing the maturity of an ESS: Leadership and Work Environment, System Capability, System Effectiveness, Organizational Encouragement and System Barriers.

\section{Literature Review}

Employee Suggestions Schemes (ESS) have come a long way [10] transiting from anonymous postboxes [11] or suggestion box to a sophisticated computer based electronic suggestion scheme [7, 12]. They are very important for organizations as they offer companies cost savings and focus innovative behavior in a useful direction.

Today the employees' ideas and innovations are extremely important in any organization because the employees are working on, owing, monitoring, and improving their processes and are experiencing the advantages or disadvantages of what they are doing [13]. Not only that they possess best knowledge, they are often in a position to identify how processes might be improved [14]. Therefore it is evident why an effective deployment of innovation is widely recognized in recent years as a mean of building organization's sustainable competitive advantage, thereby enhancing organizational performance and ultimately responsible for the survival of the organization $[15,16]$. Undoubtedly the ability of an organization to grow is dependent upon its ability to generate new ideas and to exploit them effectively for their long-term benefit [17]. Notably, in all domains of society, progress depends on the adoption of new processes, procedures or products. Innovation necessarily starts with the generation of creative ideas [18]. In other words, continuous stream of ideas is necessary as a fuel to innovation. By generating creative ideas, employees provide new solutions and possibilities for change that benefit the organization [19]. The intellectual capital of any organization is often its most valuable asset and organizational performance strongly depends on the capture, development and exploitation of the explicit and implicit knowledge that exists in the organization [20].

Literature on employee suggestion schemes has widely discussed history, nature, goals, functions, trends and evolution of the suggestion schemes [9]. Suggestion schemes create a win-win situation in organizations and the review highlighted the major benefits for all their stakeholders. Especially, as long as creativity and innovation remain key corner stones for the success of organizations, employee suggestion schemes are one of the mechanisms for organizations to improve their innovation ability.

The difficulty of sustaining outcomes has also been identified as an issue for other types of improvement mechanisms [21]. Better understanding of the determinants of sustainability in suggestion scheme could decrease this issue and organizations could systematically adopt an approach to measure and improve the ESS outcomes. An interesting topic to pursue in the field of ESS is to develop a mechanism for assessing the maturity of their ESS. Such a framework could help to overcome the gap in the literature regarding the monitoring, analyzing and improving ESS.

The variables emerging from the literature review which impact on the maturity of ESS are: Top Management Support, Supervisor Encouragement, Coworker Support, Organizational Encouragement, Support for Innovation, Communication Evaluation, Awareness, Resources, Rewards, Training, Effective System, Feedback, Implementation of ideas, Empowerment, Job Factors, Expertise, Self Efficacy and Individual Characteristics, Teamwork, Employee Participation, Job Control, Organizational Impediments, Competition, Employee Confidence, Sense of Security, Commitment and Accountability, Improvement in Process, Customer Satisfaction, Product Quality, New Revenue, Cost Saving, Employee Satisfaction [3, 8, 10-14, 22-35]. These variables are obvious supportive factors to the success of ESS. They indeed can trigger the value and volume of the suggestions, therefore they pose as the criteria necessary for the maturity of ESS.

On the other hand barriers or obstacles that hinder the success of ESS have to be mentioned as well. There are typical pitfalls noted in the literature which would impact ESS negatively [14, 29, 36-39]. The factors that proved to be barriers of ESS indeed have a negative impact on the maturity of the ESS, are the following variables: Organizational Impediments, Competition, Job Control.

The maturity of ESS should be assessed through key elements of its success. It should encompass the 
various drivers and barriers to the success of the suggestion scheme. The drivers are those variables that prove to be supportive to the success of the suggestion scheme while the barriers are those variables that prove to be barriers to the success of ESS, innovation and creativity.

A need for a tool that can be applied to assess the maturity of ESS was identified. Therefore in this paper a tool for assessment of the maturity of ESS based on [9] was proposed and discussed.

\section{Introduction and justification of the tool}

The tool for assessment of the maturity of ESS is structured around five building blocks. The five building blocks are derived from previous work that attempted to identify the factors that contribute to the maturity of ESS. These five building blocks were extracted after a thorough literature review and an empirical study where organizations reported their employee suggestion scheme practices.

The empirical study included a survey which addressed 273 users of ESS in various organizations. The gathered data was analyzed to develop the major themes using Exploratory Factor Analysis. An initial framework was created based on these results and the results were then validated through a case study method. The semi structured interview method was used to collect the data. For the purpose of this study three organizations using suggestion schemes for 5 years to 30 years were used. An open-ended interview with key members of each organization using a case study protocol guide was performed.

Afterwards a content analysis was done which is a systematic, replicable technique for compressing many words of text into fewer content categories based on explicit rules of coding. It is useful for examining trends and patterns in documents. A deductive content analysis method was used to analyze the interview transcripts. A categorization matrix that involved each factor of the maturity model was developed. The interview transcripts were then reviewed for content and coded for correspondence with maturity factors. After a categorization matrix has been developed, all the data was reviewed for content and coded for correspondence with or exemplification of the identified categories.

As already mentioned above the data collected was analyzed using an Exploratory Factor Analysis and five resultant factors were derived which are referred as the five building blocks [9].

The proposed tool should allow companies to measure their ESS performance in detail, perform analysis and plan improvements. It is hard to expect that each organization should perform consistently across each of the five building blocks (or indicators). Therefore different practices associated with each building block which require different support activities to foster them are incorporated. Organizations thus require addressing their particular strength and weakness with regard to each building block or indicator to equip themselves for the maturity of their ESS. The main goal of this tool is to help organizations to analyze each of the building blocks with the data that is uniquely useful for each organization.

Through this assessment tool organizations can develop distinctive approaches and improvement activities to sustain and yield desired results gained using their established ESS.

\section{Building Block 1:}

\section{Leadership and Top Management Support}

"How and what demonstrates Leadership and Top Management Support to the suggestion scheme?"

The Leadership and top Management Support is to be assessed and analyzed through the following four indicators: Top Management Support, Supervisor Support, Organizational Support, Coworker Support and Communication.

The Top Management support is usually exhibited through their daily actions in a range of ways. These include formulating vision and mission for ESS. They also form strategies and procedures in support of ESS and engage in awarding the employees.

Supervisors encourage and guide their subordinates for making the suggestions. Organizations establish supportive HR polices and direct the suggestions to the supervisors for their initial evaluations. They empower supervisors to make decisions and also establish a central suggestion evaluation team.

Organization facilitates its employees to take part in the suggestion scheme by organizing creativity related workshops, establishing non-rigid structures and creating a supportive organizational culture. Communication refers to the mechanism that the organization has in place to support the ESS. Organizations facilitate formal meetings among employees, create networking opportunities such as participation in conferences or creativity related activities. Organizations may also establish in house newsletter and a website to communicate and share information.

Support for innovation implies how an organization can protect it employees from disputes as a result of suggestion from their coworkers. Coworkers 
help nurture the initial idea or help in formulating joint suggestions. They may collaborate together to find solutions to issues and even provide support to promote colleagues recommendations.

Building Block 1, related indicators and measures are presented in Table 1.

\section{Building Block 2: System Capability \\ "What are features of the ESS?"}

This block can be measured and analyzed through the following five indicators: Rewards, Feedback, Evaluation, Resources, Support for Implementation.

Organizations require a mechanism to elicit employee's creative ideas and therefore they must either have a suggestion box, a manual system or an IT supported system to elicit these ideas. This system is required to be monitored regularly and the suggestions must be processed as per the organizations set policies and procedures. It is not sufficient only to receive the ideas and just appreciate them but they need to be implemented in full sprit in order the organizations can benefit from them. Organizations keep records of the suggestions received from their employees and the number of suggestions implemented after the evaluation of each of them. The success stories of its implementation must be the published and made available for other employees in order to motivate them to make new suggestions. Organizations hold promotional campaigns and make use of their bulletin boards, websites and newsletters. They hold induction programs as well. Organization usually have polices to process the suggestions within a stipulated date and provide feedback to the employer. Recognition may be handled through a well-defined reward scheme to include tangible or non-tangible benefits. Organization has an evaluation team to assess the suggestion from employees. It has established evaluation procedure and rules on evaluation process. The process of evaluation is made transparent to all employees. Resources refer to the allocation of budgets to award the suggestions and procedures to avail necessary resources for implementing a suggestion. Organizations set aside the financial budgets and establish procedures for their employees to revert if any physical resources are need to facilitate the suggestion making or suggestion implementations.

Building Block 2, related indicators and measures are presented in Table 1.

\section{Building Block 3: System Effectiveness}

"What are the outcomes of ESS and how are these outcomes evidenced in the organization?"

This block is to be measured and analyzed through the following four indicators: Profitability,
Employee Productivity, Process Improvement and Customer Satisfaction.

Organization can save cost or generate new revenues as a result of implemented suggestions. This can result in direct profit of the organization or it can have indirect benefits such as:

- Improvement in employee's perceptions with regard to job satisfaction, sense of security, employee confidence, organizational commitment and accountability.

- Reconsideration and improvement of the processes and enhancement in product or service quality.

- Customer satisfaction is improved.

Building Block 3, related indicators and measures are presented in Table1.

\section{Building Block 4: Organizational Encourage- ment}

"What are the Organizational Mechanisms to support the ESS?"

This block is to be measured and analyzed through the following four indicators: Team work, Participation, Training and Expertise.

Organizations realize the benefit of teamwork and encourage employees to collaborate and make joint suggestions. The awards would be designed to recognize the entire team. Employees can team up with colleagues from other departments as well. Employees are then subjected to creativity related or system related trainings to enhance their participation. They also organize events and workshops to stimulate creativity. Organizations make their suggestion scheme open to all employees and keep a record of suggestions received annually.

Building Block 4, related indicators and measures are presented in Table 1.

\section{Building Block 5: System Barriers}

"How well the Organizational Impediments are addressed"?

This factor is to be measured and analyzed through the following two indicators: Job Control and Competition.

Tight schedules, rigid job roles and work pressures kill employee creativity. Organizations that don't give opportunities to employees to think out of the box and just exercise task routines hinder the creativity. At the same time creating an atmosphere of competition among the employees to test their abilities hinders the suggestion submission process. The participation should be voluntary and on their own will.

Building Block 5, related indicators and measures are presented in Table 1. 
Table 1

Block 1 Survey.

\begin{tabular}{|c|c|c|}
\hline $\begin{array}{c}\text { Top } \\
\text { Management } \\
\text { Support }\end{array}$ & Characteristics & Scores \\
\hline & No visible involvement of the top management in suggestion scheme & 1 \\
\hline & Has Established vision and mission for the system & 2 \\
\hline & Has robust policies and procedures for the smooth functioning of the suggestion scheme & 2 \\
\hline & Direct involvement of the top management for awarding the best suggestions & 3 \\
\hline & Participation of the top Management in the events relating to suggestion scheme & 3 \\
\hline & Top management is active in the Review the suggestion scheme performance monthly & 3 \\
\hline & Hosting events and sponsoring events relating to creativity & 3 \\
\hline & Give strategic directives to improve the performance & 3 \\
\hline & Set up examples by involving themselves in making suggestions & 3 \\
\hline \multirow{6}{*}{$\begin{array}{l}\text { Supervisor } \\
\text { Support }\end{array}$} & Supervisors provide guidance and encouragement to submit ideas & 1 \\
\hline & Supervisor responsible for suggestion schemes as targets are set or are made accountable & 2 \\
\hline & Opportunity to discuss work related issue with supervisors prior to handing in a suggestion & 2 \\
\hline & Supervisor provides guidance and assistance in refining the ideas and is empowered & 3 \\
\hline & Supervisor and their line manager till the top are recognized for winning suggestions & 3 \\
\hline & Supervisors review monthly or quarterly reports of the suggestion scheme performance & 3 \\
\hline \multirow{10}{*}{$\begin{array}{l}\text { Organizational } \\
\text { Support }\end{array}$} & Clear suggestion guidelines and awareness to formulate suggestions & 1 \\
\hline & No evidence or support to control disruptive behavior of coworkers & 1 \\
\hline & Provision to dissolve any disputes among employees & 2 \\
\hline & Supportive organization culture & 2 \\
\hline & Employees are given suggestion target and are recognized during performance review & 2 \\
\hline & Hosts events to honor the winning suggestion & 2 \\
\hline & Provision and good support to dissolve any disputes among employees & 3 \\
\hline & $\begin{array}{l}\text { Organizations supports if an implemented suggestion needs to be replicated in other depart- } \\
\text { ments }\end{array}$ & 3 \\
\hline & $\begin{array}{l}\text { Employees can also avail the support of the central suggestion scheme team should they need } \\
\text { any help }\end{array}$ & 3 \\
\hline & Employee suggestions are centrally stored & 3 \\
\hline \multirow{6}{*}{ Communication } & Organizing Creativity simulation workshops & 3 \\
\hline & $\begin{array}{l}\text { Little evidence of open communication within the organization (Eg. formal or informal meet- } \\
\text { ings) }\end{array}$ & 1 \\
\hline & Minimum or no opportunity for networking internally and externally & 1 \\
\hline & Good evidence of open Communication within the organization & 2 \\
\hline & Constant flow of information through websites, Newsletters etc & 3 \\
\hline & There are opportunity for networking internally and externally & 3 \\
\hline \multirow{3}{*}{$\begin{array}{l}\text { Coworker } \\
\text { Support }\end{array}$} & Employee collaboration and support or each other is not very visible & 1 \\
\hline & Employees usually collaborate to make suggestions & 2 \\
\hline & Employees collaborate and submit suggestions together wirh their colleagues & 3 \\
\hline
\end{tabular}

\section{Using the Tool to assess the ESS maturity}

The most important aim of the above presented tool is to help to assess and analyses which of the building blocks are at its initial, developmental or advanced stage. This assessment tool should be used by completing the evaluation indicators from the Table 1 in order to assess the actual situation in an organization regarding the maturity of the ESS. There are two possible ways to complete this survey. Individual employees can complete the survey and average the scores to obtain the "average maturity level" and/or the system administrator completes the survey. 
Table 2

Block 2 Survey.

\begin{tabular}{|c|c|c|}
\hline Indicators & Characteristics & Scores \\
\hline \multirow{5}{*}{ Rewards } & There is a Reward for winning suggestion & 1 \\
\hline & Appreciation or award for taking part in local, regional and international suggestion contests & 1 \\
\hline & Financial and other type of rewards are set up and the reward scheme is transparent & 2 \\
\hline & Rewards are fairly calculated as per their savings & 3 \\
\hline & Established special annual award categories & 3 \\
\hline \multirow{6}{*}{$\begin{array}{c}\text { Support } \\
\text { of implementation }\end{array}$} & Organizations usually implement suggestions & 1 \\
\hline & There is an improvement in the rate of suggestion implementations & 2 \\
\hline & Provision to replicate and implement solution elsewhere in the organization & 2 \\
\hline & Awarding only implemented suggestions & 3 \\
\hline & Monitoring the system performance with regard to suggestion Implementation & 3 \\
\hline & Employees are empowered to test their creativity & 3 \\
\hline \multirow{4}{*}{ Feedback } & Set up reminders to evaluators and implementers on pending suggestions & 1 \\
\hline & Set up realistic deadlines for processing the suggestions & 1 \\
\hline & Provide encouraging feedback & 2 \\
\hline & Provision to submit the suggestion to central administrator if needed & 3 \\
\hline \multirow{6}{*}{ Evaluation } & Dedicated schedule to evaluate the suggestions & 1 \\
\hline & Dedicated Evaluation Team & 1 \\
\hline & An Evaluation Criteria & 1 \\
\hline & The evaluation procedures and team members are transparent & 2 \\
\hline & A chance to appeal the decision at least once & 3 \\
\hline & Providing reasons for rejected suggestion & 3 \\
\hline \multirow{4}{*}{ System Features } & Multiple mechanisms to the submit suggestions & 1 \\
\hline & An user-friendly electronic system to receive and timely process the suggestion & 2 \\
\hline & An user friendly electronic system and dedicated suggestion scheme administrator & 3 \\
\hline & Established Roles and responsibilities to all stakeholders with regard to suggestion scheme & 3 \\
\hline \multirow{3}{*}{ Awareness } & There are some promotional campaigns and notification about the scheme & 1 \\
\hline & There are frequent promotional campaigns & 2 \\
\hline & The scheme has a brand name & 3 \\
\hline \multirow{3}{*}{ Resources } & Availability of financial resources are limited & 1 \\
\hline & Adequate availability of financial resources and procedure to avail physical resources & 2 \\
\hline & Additional management support to source resources as required & 3 \\
\hline
\end{tabular}

Table 3

Block 3 Survey.

\begin{tabular}{c|l|c}
\hline Indicator & Characteristics & Scores \\
\hline \multirow{3}{*}{ Profitability } & There is no evidence of new revenue generation or cost savings & 1 \\
\cline { 2 - 3 } & There is adequate evidence of new revenue generation or cost savings & 2 \\
\cline { 2 - 3 } & There is good evidence of new revenue generation or cost savings & 3 \\
\hline \multirow{3}{*}{$\begin{array}{c}\text { Productivity } \\
\text { improvements }\end{array}$} & Employees are not satisfied, confident or lack Accountability & 1 \\
\cline { 2 - 3 } & Employees are generally satisfied, confident show sense of responsibility & 2 \\
\cline { 2 - 3 } & Employee are mostly satisfied, confident, accountable and take responsibility & 3 \\
\cline { 2 - 3 } $\begin{array}{c}\text { Customer } \\
\text { satisfaction }\end{array}$ & No process improvements taking place and no impact on products or services quality & 2 \\
\cline { 2 - 3 } & This is a regular activity in the organization and visible in product/service quality & 3 \\
\cline { 2 - 3 } & Adequate Evidence of improvement in customer satisfaction & 2 \\
\cline { 2 - 3 } & Good evidence of improvement in customer satisfaction & 3 \\
\hline
\end{tabular}


Table 4

Block 4 Survey.

\begin{tabular}{c|l|c}
\hline Indicator & Characteristics & Scores \\
\hline \multirow{5}{*}{$\begin{array}{c}\text { Employee } \\
\text { Participation }\end{array}$} & Participation is suggestion scheme is limited to few employees & 1 \\
\cline { 2 - 3 } & Number of suggestion received are not known or made public & 1 \\
\cline { 2 - 3 } & Scheme open to all to participate & 2 \\
\cline { 2 - 3 } & Evidence available to demonstrate the actual participation (No. of suggestions) & 2 \\
\cline { 2 - 3 } & Organization or employees win awards for their suggestions & 3 \\
\cline { 2 - 3 } & Sets participation targets eg (min suggestions per year) & 3 \\
\cline { 2 - 3 } & Encourages suggestion for any area and not necessarily for cost savings & 3 \\
\cline { 2 - 3 } Team work & No strict boundary between job role and creativity & 3 \\
\hline & No provision for team suggestions & 2 \\
\cline { 2 - 3 } & Team suggestion are encouraged & 3 \\
\cline { 2 - 3 } & Team Rewards are established & 3 \\
\cline { 2 - 3 } & Teams make high value suggestions & 2 \\
\hline & No formal trainings are offered & 3 \\
\cline { 2 - 3 } & Training programs are offered to use suggestion scheme & 1 \\
\cline { 2 - 3 } & Creativity related workshops and trainings are regular and assessed & 2 \\
\hline & Organization has few talented employees & 3 \\
\cline { 2 - 3 } & Organization has talented and experienced employees who make more suggestion when com- & 2 \\
\cline { 2 - 3 } & pared to others & 2 \\
\cline { 2 - 3 } & High value suggestions are elicited from experienced employees & 2 \\
\cline { 2 - 3 } & Suggestions get awarded at local or international competitions & 2 \\
\hline
\end{tabular}

Table 5

Block 5 Survey.

\begin{tabular}{c|l|c}
\hline Indicator & Characteristics & Scores \\
\hline \multirow{5}{*}{ Job Control } & Little flexibility in working environment & 1 \\
\cline { 2 - 3 } & Usually standard work routines and work under pressure mostly & 1 \\
\cline { 2 - 3 } & Moderate flexibility in working environment & 2 \\
\cline { 2 - 3 } & Usually no standard work routines and work under pressure & 2 \\
\cline { 2 - 3 } & Good flexibility in working environment & 3 \\
\cline { 2 - 3 } & No standard work routines or work pressures & 3 \\
\hline \multirow{3}{*}{$\begin{array}{l}\text { Employees feel pressured to make suggestions as they believe that they are judged for their } \\
\text { performance through the suggestion scheme }\end{array}$} & 1 \\
\cline { 2 - 3 } & $\begin{array}{l}\text { Employees are somewhat informed that participation is not mandatory but are tied indirectly } \\
\text { for its success through different target setting }\end{array}$ & 2 \\
\cline { 2 - 3 } & $\begin{array}{l}\text { Employees are well informed that they participate at suggestion scheme at their own will and } \\
\text { they are not judged for their performance and therefore are tied to any targets }\end{array}$ & 3 \\
\hline
\end{tabular}

Table 6

Maturity stages of ESS for the distinct blocks and the overall result.

\begin{tabular}{c|c|c|c|c|c|c}
\hline Block 1 Score & Block 2 Score & Block 3 Score & Block 4 Score & Block 5 Score & Overall result & Maturity level \\
\hline 1 to 6 & 1 to 17 & 1 to 4 & 1 to 5 & 1 to 3 & $\leq 35$ & Initial Stage \\
\hline 7 to 21 & 18 to 25 & 5 to 10 & 6 to 12 & 4 to 6 & $>35$ to 74 & Developmental Stage \\
\hline 22 and above & 26 and above & 11 and above & 13 and above & 7 and above & $>74$ & Advanced stage \\
\hline
\end{tabular}

For example the building block 1 can be illustrated of demonstrating basic practices of having a facility to make suggestions but there is no evidence of top management is yet supporting the ESS. Same can be illustrated as having initiated a specific action but yet no evidence of full use of the same. While evidences such as direct involvement of top management in various forms reflects that scheme has gained enough support which is essential for the success of an ESS.

The next step is to calculate the subtotals for each block and the total score using the introduced 
scores of each indicator. The results for each block individually and the total score should give insights and a valid picture of the maturity level of the organizational ESS trough evaluating the existing practices exercised in a distinct organization. The classification on the basis of the scores presented in Table 6 will farther classify the distinct blocks as well as the whole organization into the adequate maturity level of its ESS.

If needed a follow-up analysis will have to be considered, followed by some improvement initiatives in order to introduce new and/or change the existing practices to increase the effectiveness and efficiency of the ESS.

Using this tool, organization can pinpoint the indicators that require fostering for its maximum benefits. The task is to identify each of the blocks and their indicators that exhibit weak existence or result and to develop potential strategies to foster the respective indicator.

After the improved ESS will be well established, a new assessment with the tool might follow-up to evaluate the performance and maturity of the updated ESS.

\section{Discussion}

One of the most important benefits of the implementation of the presented tool is that it gives a fair idea about the maturity levels of each building block as well as the overall maturity of an organization's employee suggestion scheme. Although, the sustainability [8] and critical success factors have been widely cited [9], there has been no research reported on quantitatively assessing these factors. Moreover the effectiveness or sustainability is attributed to elements like number of suggestions, number of suggestions implemented [8], awarded and cost saved. Definitely these are important aspects; however, as noted in the literature, it is essential to foster the enablers for its success [28]. In this light we can argue that the tool offers a new way of analyzing the existence and evidence of factors that foster the success of an ESS. It is unique in a way that not only identifies a factor (indicator), but it recommends the associated practices and leads an organization from initial maturity stage of an ESS to its advanced stage.

The proposed tool has taken into consideration a number of factors reported in the literature [9]. In addition, this paper adds further value by giving guidelines for quantification of the maturity levels of employee suggestion schemes. Given that each of the building blocks has various indicators which are widely understood as essential factors that con- tribute to the effective employee suggestion scheme, it can be supposed that this tool provides a valid assessment from which organizations can draw a road map for improvement initiatives. The individual blocks as shown in the Table 6 has practices associated with each stage. A score between 1 and 6 for block 1 indicates that it is in initial level of maturity and a total score of up to 35 overall implies an initial stage. Thus the organizations can draw a map for individual factors and overall system based on criteria in Table 6. For the developmental stage the scores for individual blocks as well as overall scores are also drawn. The Advanced stage of ESS is achieved with an overall score of more than 74 . These qualitative scores give a quick analysis as to which factor or indicator requires attention. In addition the individual practices are also assigned score of 1 to 3 from its basis form to advanced form. Therefore a corresponding practice at an initial state with a score of 1 can be improved to its next level.

\section{Conclusions}

Employee suggestion schemes are used by the organization to elicit employee creative ideas. If an employee suggestion scheme is used effectively, it can pave a way for organizations to build on its innovative capability. Given that the maturity of the employee suggestion scheme depends on many factors, it is essential that each of the factors is fostered to yield best possible results.

This paper proposes a tool to assess the maturity of employee suggestion scheme. The new tool helps to conceptualize three stages of ESS maturity by introducing five building blocks for assessing the maturity: Leadership and Work Environment, System Capability, System Effectiveness, Organizational Encouragement and System Barriers. Each of these blocks integrates several indicators of ESS practices.

On the basis of the elaborated assessment/ grading scale the three stages of ESS maturity level can be determined: The initial stage indicates that the organization has minimum requirements in place with respect to their ESS; as such it requires nurturing and adopting the practices associated with the development stage. The development stage indicates moderate existence of required support elements, but each of these indicators to be fostered further to achieve a higher level of performance - the advanced stage of ESS maturity.

Future studies can be carried out to illustrate the applicability of the tool as well as to develop industry specific benchmark values for the maturity of ESS. 


\section{References}

[1] Milner E., Kinnell M., Usherwood B., Employee suggestion schemes: a management tool for the 1990s?, Library Management, 16, 3-8, 1995.

[2] Cooley R.E., Helbling C., Fuller U.D., Knowledge, Organization and Suggestion Schemes, Management of Industrial and Corporate Knowledge, 47-56, 2001.

[3] Arthur J.B., Aiman-Smith L., Arthur J.E.F.B., Gainsharing and organizational learning: suggestions over time an analysis of employee, Management, 44, 737-754, 2010.

[4] Fuller U., Helbling C., Cooley R., Suggestion schemes as information and knowledge management system, Proceedings of the 7th Annual UKAIS Conference, Leeds Metropolitan University, England, UK, 226-234, 2002.

[5] Buech V.I.D., Michel A., Sonntag K., Suggestion systems in organizations: what motivates employees to submit suggestions?, European Journal of Innovation Management, 13, 507-525, 2010.

[6] Pissarra J., Jesuino J.C., Idea generation through computer-mediated communication: The effects of anonymity, Journal of Managerial Psychology, 20, 4, 275-291, 2005.

[7] Fairbank J.F., Williams S.D., Motivating Creativity and Enhancing Innovation through Employee Suggestion System Technology, Creativity and Innovation Management, 10, 68-74, 2001.

[8] Rapp C., Eklund J., Sustainable Development of a Suggestion System: Factors Influencing Improvement Activities in a Confectionary Company, Human Factors, 17, 79-94, 2007.

[9] Lasrado F.M., Arif Aftab R., Determinants of an ESS, International Journal of Quality and Reliability Management, 182-210, 2015.

[10] Arif M., Aburas H.M., Al Kuwaiti A., Kulonda D., Suggestion Systems: A Usability-Based Evaluation Methodology, Journal of King Abdulaziz UniversityEngineering Sciences, 21, 2, 61-79, 2010.

[11] Crail M., Fresh ideas from the floor, Personnel Today, 30, 2006.

[12] Ahmed A.M., Staff Suggestion Scheme (3Ss) within the UAE Context: Implementation and Critical Success Factors, International Journal of Education, Business and Society: Contemporary Middle Eastern Issues, 2, 2, 153-167, 2009.

[13] Du Plessis A.J., Marx A.E., Wilson G., Generating ideas and managing suggestion systems in organisations: some empirical evidence, International
Journal of Knowledge, Culture and Change Management, 8, 133-140, 2008.

[14] Neagoe L.N., Klein V.M., Employee suggestion system (kaizen teian) the bottom-up approach for productivity improvement, Control, 10, 26-27, 2009.

[15] Koc T., Ceylan C., Factors impacting the innovative capacity in large-scale companies, Technovation, 27, 105-114, 2007.

[16] Khairuzzaman W., Ismail W., Abdmajid R., Framework of the Culture of Innovation: A Revisit, Jurnal Kemanusiaan, 9, 38-49, 2007.

[17] Flynn M., Dooley L., Cormican K., Idea management for, International Journal of Innovation Management, 7, 4, 417-442, 2003.

[18] Rietzschel E.F., Nijstad B.A., Stroebe W., The selection of creative ideas after individual idea generation: choosing between creativity and impact, British journal of psychology, 101, 47-68, 2010.

[19] Madjar N., The Contributions of Different Groups of Individuals to Employees' Creativity, Advances in Developing Human Resources, 7, 182-206, 2005.

[20] Reychav I., Sharkie R., Trust: an antecedent to employee extra-role behavior, Journal of Intellectual Capital, 11, 2, 227-247, 2010.

[21] Bateman N., Sustainability: the elusive element of process improvement, International Journal of Operations \& Production Management, 25, 3, 261-276, 2005 .

[22] Lloyd G.C., Thinking beyond the box, Health Manpower Management, 22, 37-9, 1996.

[23] Klijn M., Tomic W., A review of creativity within organizations from a psychological perspective, Journal of Management Development, 29, 322-343, 2007.

[24] Bartol K.M., Srivastava A., Encouraging Knowledge Sharing: The Role of Organizational Reward Systems, Journal of Leadership \& Organizational Studies, 9, 64-76, 2000.

[25] Darragh-Jeromos P., System that works for you, Super Vision, 66, 7, 18, 2005.

[26] Leach D.J., Stride C.B., Wood S.J., The effectiveness of idea capture schemes, International Journal of Innovation Management, 10, 325-35, 20060.

[27] Lloyd G.C., Stuff the suggestion box, Total Quality Management, 10, 869-875, 1999.

[28] Marx A.E., Management commitment for successful suggestion systems, Work Study, 44, 16-18, 1995.

[29] McConville J., Innovation through involvement, The TQM Magazine, 2, 295-297, 1990. 
[30] Rice G., Individual values, Organizational Context, and self-perceptions of employee creativity: Evidence from Egyptian organizations, Journal of Business Research, 59, 2, 233-241, 2006.

[31] Shalley C.E., Gilson L.L., What leaders need to know: A review of social and contextual factors that can foster or hinder creativity, The Leadership Quarterly, 5, 33-53, 2004.

[32] Tatter M.A., Tuning Ideas into Gold, Management Review, 64, 4, 1975.

[33] Van Dijk C., Van den Ende J., Suggestion system: transferring employee creativity into practicable ideas, R\&DD Management, 32, 387-395, 2002.

[34] Frese M., Teng E., Wijnen C.J.D., Helping to improve suggestion systems: predictors of making suggestions in companies, Journal of Organizational Behavior, 20, 1139-1155, 1999.

[35] Winter, Staff suggestion schemes, Management Services, 53, 6-7, 2009.
[36] Anderson T.A., Veillette A., Contextual Inhibitors of Employee Creativity in Organizations: The Insulating Role of Creative Ability, Group \& Organization Management, 34, 330-357, 2008.

[37] McLean L.D., Organizational Culture's Influence on Creativity and Innovation: A Review of the Literature and Implications for Human Resource Development, Advances in Developing Human Resources, 7, 226-246, 2005.

[38] Sadi M.A., Al-Dubaisi A.H., Barriers to organizational creativity: The marketing executives' perspective in Saudi Arabia, Journal of Management Development, 27, 574-599, 2008.

[39] Wong C.-Keung S., Pang W.-L.L., Barriers to creativity in the hotel industry - perspectives of managers and supervisors, International Journal of Contemporary Hospitality Management, 15, 29-37, 2003. 